International Journal of Advanced Trends in Computer Science and Engineering

Available Online at http://www.warse.org/IJATCSE/static/pdf/file/ijatcse37832019.pdf

https://doi.org/10.30534/ijatcse/2019/37832019

\title{
A Neural-Fuzzy Network Approach to Employee Performance Evaluation
}

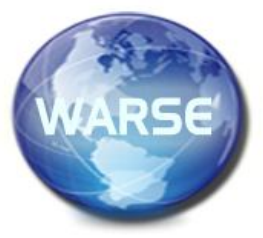

\author{
Caryl Charlene Escolar-Jimenez, DBA ${ }^{1}$, Kichie Matsuzaki, $\mathbf{P h D}^{2}$, Reggie C. Gustilo, $\mathbf{P h D}^{3}$ \\ ${ }^{1}$ Tokyo City University, Japan, caryl@tcu.ac.jp \\ ${ }^{2}$ Tokyo City University, Japan, matsuzak@tcu.ac.jp \\ ${ }^{3}$ De La Salle University, Manila, Philippines, reggie.gustilo@dlsu.edu.ph
}

\begin{abstract}
This neuro -fuzzy system enables the algorithm to identify performing and non-performing employees as organizations currently use several traditional employee evaluation performance methods that utilizes different approaches that are inaccurate and subjective by nature and usually deficient in approximating the accurate capability and nature of employee performance. Results revealed that this artificial intelligence technique utilizing the neuro-fuzzy profiling system, optimizes the objective function in the employee quality evaluation and determines the most distinctive employees deserving career advancement or those who further need appropriate training and development in the achievement, leadership and behavior categories. Since the coefficients of Neural Network can be tuned to the manager's evaluation results, the logic of the overall judgment can be adjusted to the characteristics of the department. The evaluation of this system is also performed with the same evaluation logic of the objective input values thus, the objectivity and transparency of the evaluation are extremely high. This enables HR and decision makers in the organization to truly understand employee strengths and weaknesses that is also an essential part in promoting a positive company culture unlike the traditional employee performance evaluation methods still being adopted by many organizations at present that is impaired with unreliability and rating errors.
\end{abstract}

Key words: Artificial intelligence, Employee performance evaluation, HR analytics, Neural-Fuzzy network, Promotion, Training and development, Management

\section{INTRODUCTION}

Managing human talent is integral as the right people for the right job in the right time significantly contributes to the current and future performance of a firm. Effective talent management in all $4 \mathrm{HR}$ functions namely: hiring and selection, compensation and benefits, training and development and performance management involves crucial planning and coordination from the HR department.

Many businesses are adopting applications of technology or artificial intelligence platforms to find near-optimal solutions to difficult problems [1] and these subsequently, optimizes speed, cost savings and precision in the operational and customer experiences of the organization. This article is part of the HR analytics framework complimentary research series of the researchers as indicated in Figure 1 that aims to substantially contribute to the synergistic planning and decision making of all core business processes of an organization.

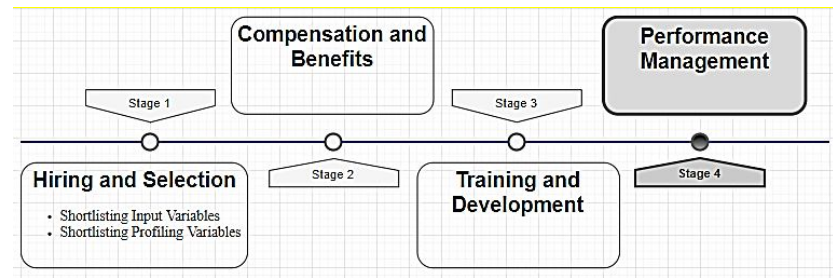

Figure 1: HR Analytics Functional Area Framework

Intellectual work is increasing in the integral areas of human resources primarily in employee evaluation. An effective employee performance evaluation determines the capabilities, knowledge, skills and other attributes of existing employees that contributes to the long-term success of organizations as these depend on having the right people in the right jobs at the right time [2]. With the increasing competition in global markets, all organizations realize the importance of retaining their most talented employees [3] as their source of competitive advantage.

An employee evaluation is an on-going process that require routine feedback and documentation about an employee's performance in terms of their work quality, attitude and job skills. This serves as a constructive tool to communicate job expectations and goals in a definite time period relative to the collective objectives set by an organization. This dialogue also creates insights into the motivations of individuals and leads to a greater understanding on the specific training and development needs of employees. Also, given the advancement of networks, increasing collaborative work at home or remote offices makes it more difficult for managers to evaluate accurate employee performances rather than the conventional face-to-face work environments.

However, given its contribution to the overall success to organizations, human resources are still facing numerous constraints in the quality of personnel evaluation that is both complex and challenging [4] as studies highlighted issues 
regarding its time-consuming and costly process. Furthermore, in a digital society, there is a need to further develop the objectivity and transparency of the performance evaluation as its practical application effect is not apparent granting its difficulty in removing the subjectivity and fuzziness in the process of decision making [5] by individuals. This necessitates organizations to provide concrete evidence of the actual evaluation content that can withstand employee complaints or in extreme cases, legal issues such as employee discrimination lawsuits caused by performance evaluation problems that could have been prevented or remedied beforehand.

These consequently, also causes delays in the evaluation process in the promotion, termination, salary increase, or job change of an employee. Thus, there is now apparent pressure with line managers and the organization to come up with a required effective employee evaluation system to address these concerns.

This study aims to propose a useful approach to quantify and implement the evaluation parameters [6] to minimize subjective-ness and vagueness where the usual information is presented in expressions or words in a natural language without a precise output [7]. Contemporary methods in evaluation are artificial intelligence techniques that are fuzzy sets and neural networks to minimize the subjective judgement in decision making between an appropriate and inappropriate employee [2]. This approach is to cluster a group of employees in an organization where it considers the membership accuracy with a range of certain values [8]. These techniques are also mostly popular in decision-based structures in proposed systems in engineering communications [9] and in face detection [10].

Additionally, the proposed evaluation method in this research utilizes objective data to evaluate employees according to a common evaluation logic that therefore, reduces not only the load on the manager who performs the evaluation and but also guarantees objectivity and transparency in the process.

As a basic policy of this employee performance evaluation is according to three categories namely: Achievement Category, Leadership Category and Behavior Category to perform appropriate evaluation for promotion that is integrated in the evaluation of each category.

The evaluation scores on each criteria are based on a decent rubric that is illustrated in Table 1 below. This rubric assures that each criteria will be scored properly by the evaluator by filtering out subjectivity in assessing individual performance before application of the neural-fuzzy technique.
The traditional evaluation method uses a certain weight on each criteria that sums up to 100 percent. The artificial neural network then makes the judgement process more scientific by solving complex nonlinear problems in uncertain and vague environment by improving the quality and speed of personnel quality evaluation [5] by establishing an extensive performance evaluation aligned to these 3 categories that will not only address major issues of a manager's advanced evaluation skills but also design a comprehensive evaluation system that would benefit the organization in the long term.

Table 1: Rubric for Assessing Individual Performance

\begin{tabular}{|c|l|}
\hline $\begin{array}{c}\text { Employee } \\
\text { Parameter } \\
\text { Rating }\end{array}$ & \multicolumn{1}{|c|}{ Parameter Description } \\
\hline $91-100$ & Outstanding in all categories \\
\hline $81-90$ & Very satisfactory except in 1 trait \\
\hline $71-80$ & Very satisfactory except in 2 traits \\
\hline $61-70$ & Very satisfactory except in 3 traits \\
\hline $51-60$ & Satisfactory in all categories \\
\hline $41-50$ & Moderately satisfactory except in 1 trait \\
\hline $31-40$ & Moderately satisfactory except in 2 traits \\
\hline $21-30$ & Moderately satisfactory except in 3 traits \\
\hline $11-20$ & Needs improvement \\
\hline $0-10$ & Poor \\
\hline
\end{tabular}

\section{PROBLEM STATEMENT}

In the talent management process, the employee performance evaluation is one of the few processes that gives anxiety to most managers.

The evaluation process involves numerous processing and preparation time and cost as evaluations are required to be accomplished at least annually. This becomes a dilemma for any human resource department once delays or inconsistencies occur, as the goal of employee evaluation is to assess and identify patterns in an employee's performance over multiple years or a certain period of time. This is crucial as this leads to strategic decisions linked to employee retention, career advancement and training needs.

The traditional evaluation methods are usually subjective, biased and inaccurate. This research proposes an intelligent and straightforward approach in evaluating employee performance. A neuro-fuzzy system was utilized to enable the algorithm to identify performing and non-performing employees to detect patterns and make predictions [11]. This fuzzy profiling and evaluation algorithm measure the employee performance in all three broad categories namely: achievement, leadership and behavior. Overall, the proposed intelligent system does not only enable human resource department to objectively identify and retain deserving employees but to also provide accurate feedback and resolve performance evaluation issues. 


\section{DESIGN PROCESS}

The proposed neuro fuzzy system will enable company managers to easily identify the strengths and weaknesses of the employees by profiling them into three major areas namely: achievement, leadership and behavior. Those employees who meet the minimum standards in all three major areas will only qualify for promotion. This system will eliminate the subjectivity that occurs resulting from the traditional scoring system used in the evaluation process. Figure 2 showed the overall block diagram of the neurofuzzy profiling and evaluation algorithm. The basis for the employee profiling is to classify both quantitative and qualitative factors by obtaining an objective evaluation criteria by measuring the consistency of the productivity and quality of work delivered to the organization. The three broad categories have evaluation parameters for all employees in general regardless of field or position. For the Achievement Category: These consider the attendance, discipline and work output traits of an employee by assessing how and if the employee met those goals. For the Leadership Category: These identifies the teamwork and leadership traits that examine the potential attributes of an employee's ability to anticipate the need for change, balance risk, communicate ideas and take necessary action. For the Behavior Category: These recognizes the dependability, behavior and integrity traits on what employees do and how employees react to work processes. Finally, those employees who perform in all three broad categories will be considered for promotion as the parameters set in these areas eliminates uncertainty and subjectiveness in the formal management system of the employee evaluation.

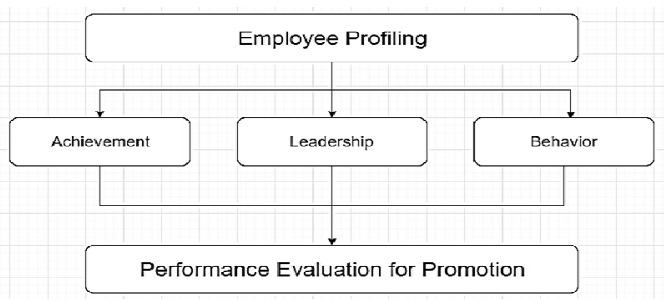

Figure 2: Overall Block diagram for Neuro-Fuzzy Profiling Algorithm

The proposed system will profile the employees based on the three major qualifications namely achievement, leadership and behavior. Fuzzy logic is used to correctly obtain the individual performance given a set of criteria.

\subsection{Achievement category}

The first employee qualification is the Achievement category that considers the attendance, discipline and work output traits of an employee. These are vital aspects that determine the quality of its goal attainment. These three criteria are inputs to a dual fuzzy logic process as shown in Figure 3 below. The minimum evaluation score set in these traits is 50. If an employee receives a rating below the minimum evaluation score in one or two traits, this will guide managers to recognize the specific training and development needs of an employee. While an employee who passes in all three traits will receive an attractive score in the achievement category that will be interpreted accordingly in the Fuzzy Associative Matrix in Figure 5.

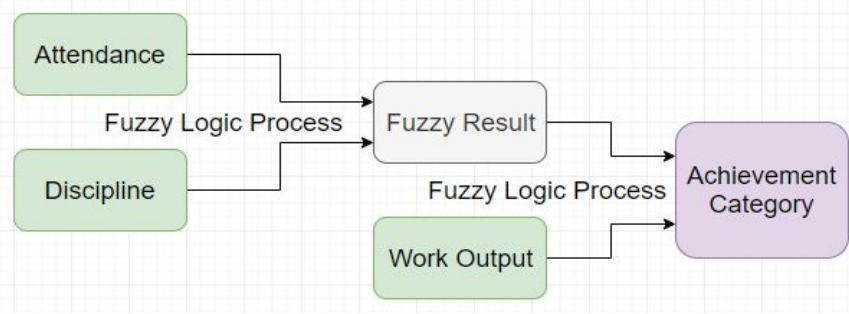

Figure 3: Fuzzy Logic Process in the Achievement Category

The first fuzzy logic process was done between the attendance and the discipline. Figure 4 below shows the fuzzy membership function for the attendance and discipline traits.

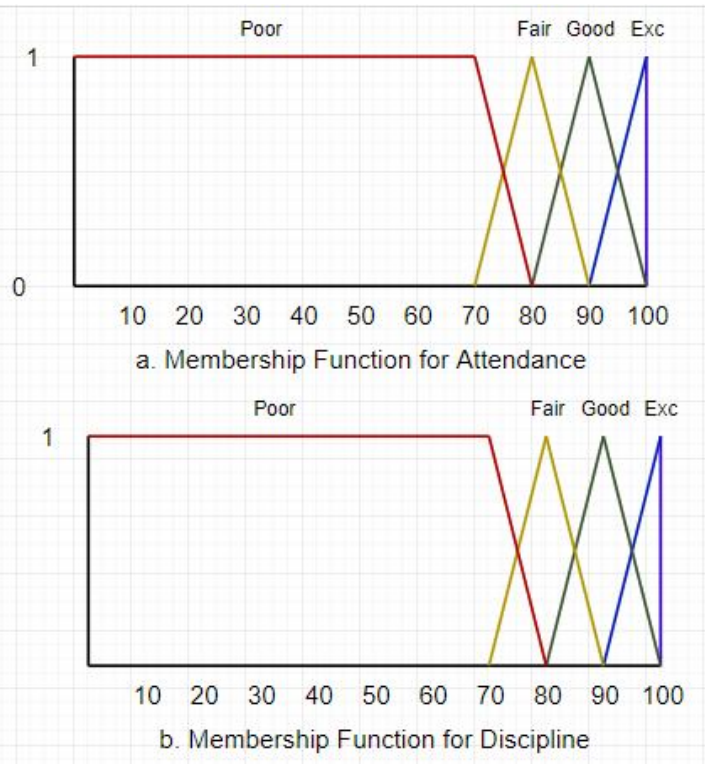

Figure 4: Fuzzy Membership Function for Attendance and Discipline.

The output in the fuzzy logic process between the attendance and discipline undergo a very strict rule. If an employee receives a failed rating in any trait, the employee is totally not eligible for promotion as the parameters set in the evaluation criteria objectively measures the consistency of the productivity and quality of work of the employee, thus, a 
failed rating indicates non-performance. This is a more straightforward approach unlike the traditional evaluation methods utilized by HR in the past. The fuzzy associative matrix guidelines is illustrated in Figure 5.

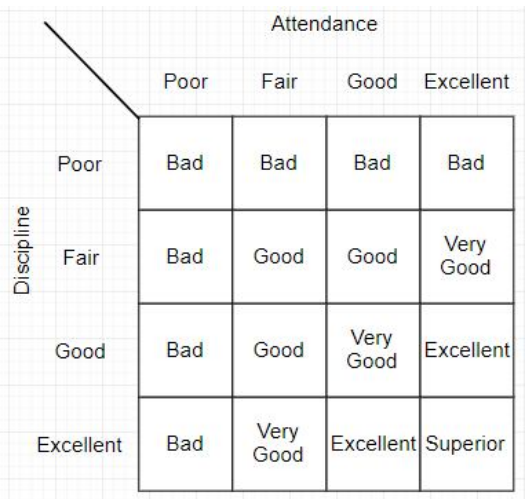

Figure 5: Fuzzy Associative Matrix for Attendance and Discipline

The result of the fuzzy inference algorithm between attendance and discipline is further fuzzified to the work output criteria. The fuzzy membership functions and fuzzy associative matrix for this process is shown in Figure 6 and Figure 7. The output for this stage describes the employee performance for his achievement.

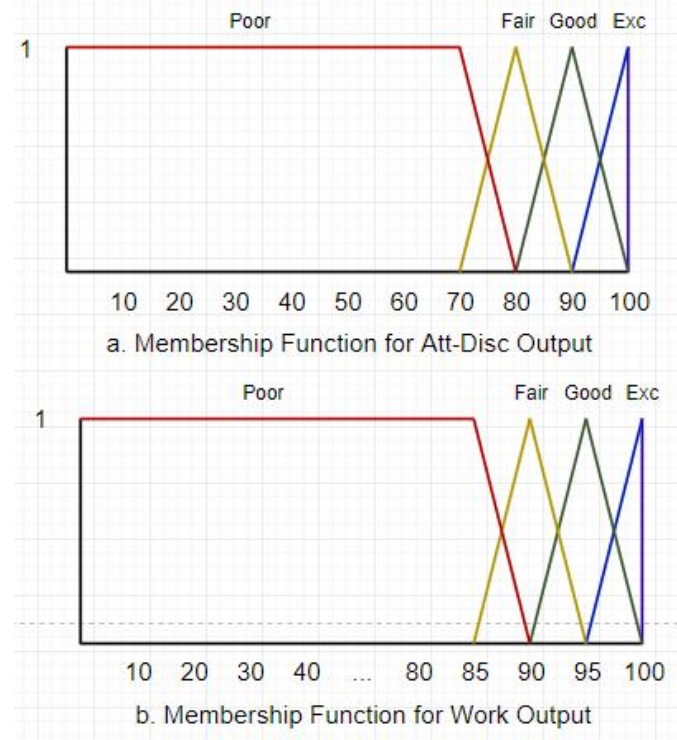

Figure 6: Fuzzy Membership Function between the results of fuzzification of the attendance and discipline and the work output

\begin{tabular}{|c|c|c|c|c|}
\hline 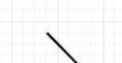 & & $\begin{array}{l}\text { ndance } \\
\text { euzzy L }\end{array}$ & $\begin{array}{l}\text { and Discip } \\
\text { gic Result }\end{array}$ & line \\
\hline & Poor & Fair & Good & Excellent \\
\hline Poor & Bad & $\mathrm{Bad}$ & Bad & Bad \\
\hline Fair & Bad & Good & Good & $\begin{array}{l}\text { Very } \\
\text { Good }\end{array}$ \\
\hline Good & Bad & Good & $\begin{array}{l}\text { Very } \\
\text { Good }\end{array}$ & Excellent \\
\hline Excellent & Bad & $\begin{array}{l}\text { Very } \\
\text { Good }\end{array}$ & Excellent & Superior \\
\hline
\end{tabular}

Figure 7: Fuzzy Associative Matrix in the Achievement category

\subsection{Leadership category}

The second category for an individual's performance is the Leadership category where it considers the individual's teamwork abilities and leadership traits. These inputs are fuzzified to determine the individual's performance level on leadership. Figure 8 below shows the fuzzy logic process for leadership category.

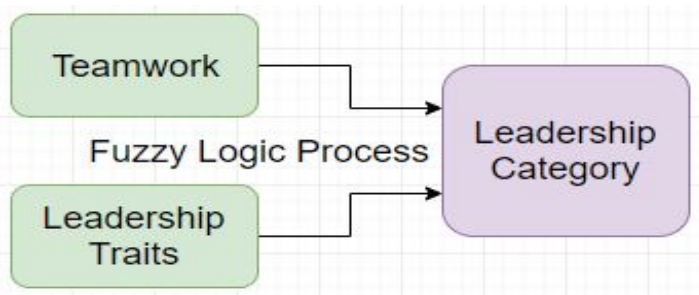

Figure 8: Fuzzy Inference System in the Leadership category

Figure 9 and Figure 10 illustrates the membership functions of the inputs and the fuzzy associative matrix for the leadership category.

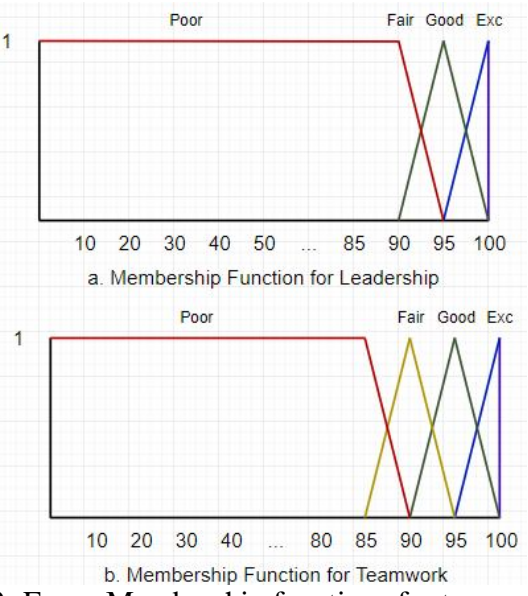

Figure 9: Fuzzy Membership functions for teamwork and leadership traits of the employee 


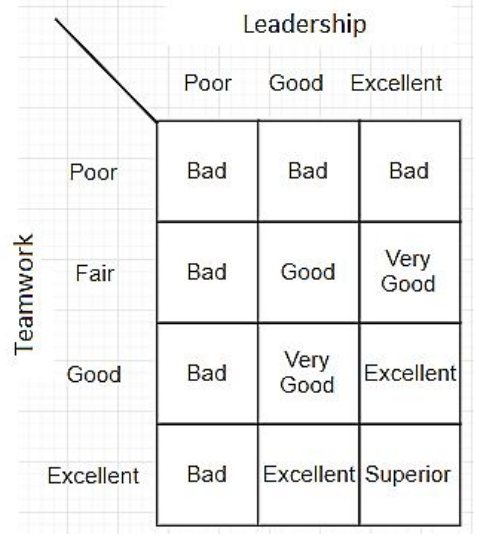

Figure 10: Fuzzy Associative Matrix in the Leadership category

\subsection{Behavior Category}

The third qualification for employees is the Behavior category that have three distinct criteria namely: dependability, behavior and integrity wherein a dual-stage fuzzy logic system was used to demonstrate an individual's behavior. Figure 11, 12 and 13 reveal the behavior category fuzzy logic system process, the inputs of the membership functions and the behavior category fuzzy associative matrix respectively.

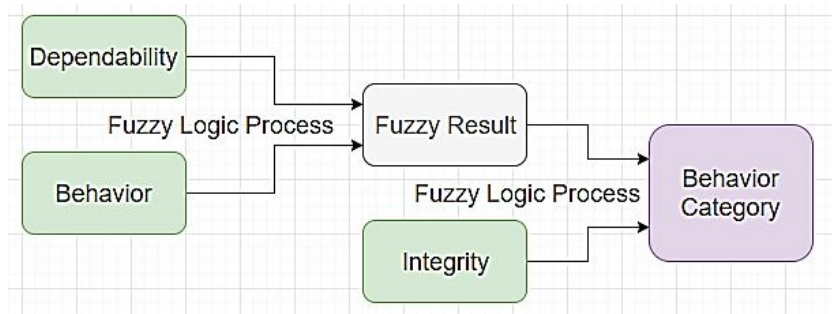

Figure 11: Behavior category Fuzzy Inference System Block diagram
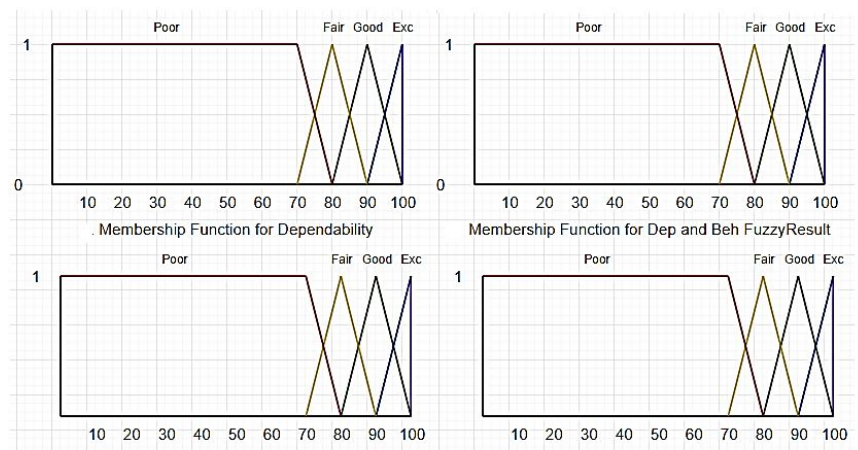

Membership Function for Behavior

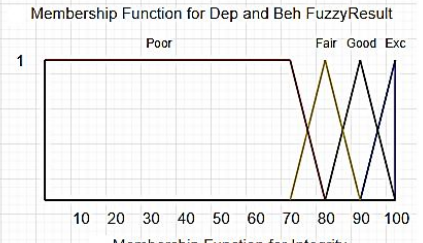

Figure 12: Fuzzy membership functions for the inputs in the behavior category
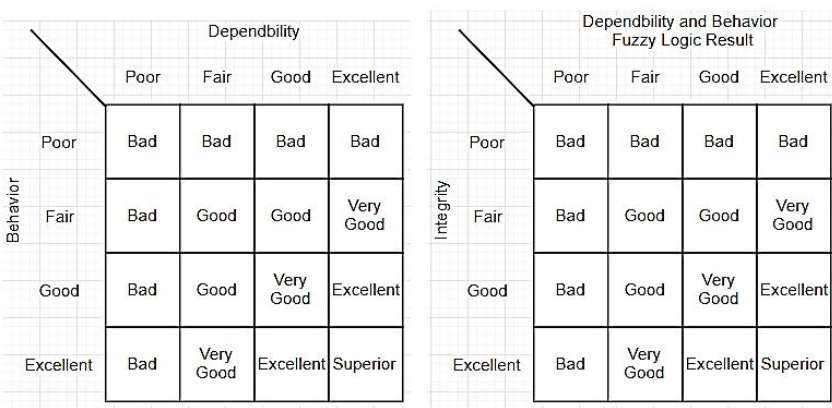

Figure 13: Fuzzy Associative Matrices Used for behavior category

\subsection{Employee Performance Assessment using Artificial Neural Network.}

After profiling the employees with their respective achievement, leadership and behavior categories, the organization can now identify not only their distinct individual needs of the employees but also perform objective decisions whether to promote, train and develop in 1 or 2 areas or terminate them. Those employees who have demonstrated meritorious performances in all three categories are considered for promotion while those nonperforming individuals are eliminated from the network. The artificial neural network is designed to evaluate the employee's performance for promotion. This system rejects every employee with at least one criteria that is unsatisfactory and gives a strict numerical point system to those who are qualified. The dataset consists of 1000 sample employee data that is used in training, evaluation and testing of the neural network. Figure 14 shows the basic structure of the artificial neural network.

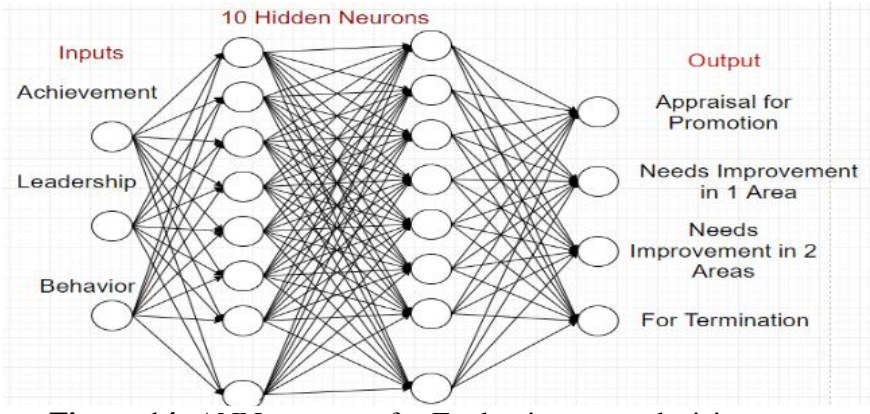

Figure 14: ANN structure for Evaluation score decisions on promotion, training and termination 
The ANN structure will produce two outputs namely: a decision output and an appraisal output. The decision output will produce 4 binary values while the appraisal output will produce either a binary or continuous value depending on the decision output scores. The resulting outputs provides a comprehensive evaluation with a tuned Neural Network based from preferences of the manager or the department. This now serves as an integral tool for objective decision making where scores can be directly added in the 3 categories which eliminates unreliability and rating errors usually found in employee performance evaluations.

\section{DISCUSSION OF RESULTS}

\subsection{Employee Profiling Results}

The fuzzy profiling system was used in 100 employees with individual ratings for the 8 criteria. Table 2 shows the result after proposing the employee profiling system.

Table 2: Result of Profiling 100 Employees

\begin{tabular}{|c|c|}
\hline Category & $\begin{array}{c}\text { Number of } \\
\text { Employees who } \\
\text { satisfied the } \\
\text { Category }\end{array}$ \\
\hline $\begin{array}{c}\text { Above minimum requirements in } \\
\text { all Areas }\end{array}$ & 19 \\
\hline Needs Improvement in one Area & 14 \\
\hline Needs Improvement in Two Areas & 13 \\
\hline Poor Performance in all Areas & 54 \\
\hline Total & 100 \\
\hline
\end{tabular}

The first 20 employees are profiled by the system. Figure 15 exhibits the profile of individual performing and nonperforming employees in the achievement, leadership and behavior categories which are the results of the fuzzy logic profiling. A cutoff rating of 50 was assigned to indicate an unsatisfactory performance on a certain category while those individuals who display exemplary behavior will be emphasized in all categories.

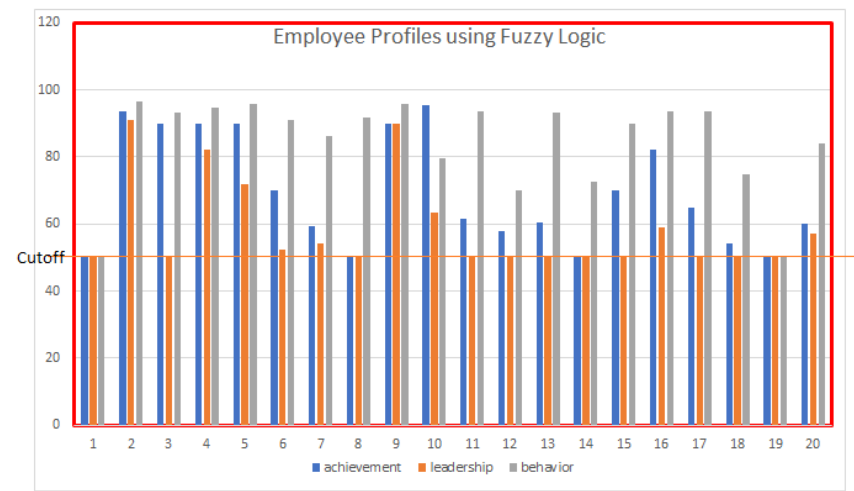

Figure 15: Employee profiles based on achievement, leadership and behavior.

\subsection{Result of artificial neural network}

The artificial neural network dataset consists of 1000 sample data that has 10 hidden layers that utilized the LevendergMarquardt as its training algorithm. Table 3 below summarizes the performance of the artificial neural network.

Table 3: Dataset used in Artificial Neural Network

\begin{tabular}{|c|c|c|c|}
\hline Samples & $\begin{array}{c}\text { Mean } \\
\text { Square } \\
\text { Error }\end{array}$ & $\begin{array}{c}\text { Coefficient } \\
\text { of } \\
\text { Correlation }\end{array}$ \\
\hline Training & 700 & $1.62 \mathrm{e}-19$ & 0.99999 \\
\hline Validation & 150 & $2.11 \mathrm{e}-8$ & 0.99999 \\
\hline Testing & 150 & $8.63 \mathrm{e}-9$ & 0.99999 \\
\hline
\end{tabular}

The dataset consisting of 1000 employees are evaluated and profiled utilizing both the traditional method of evaluation and the proposed Neuro-Fuzzy profiling system. The traditional evaluation method uses a certain weight on each criteria that sums up to 100 percent. The breakdown of each weight are shown in Table 4.

Table 4: Breakdown of weight ratings on each criteria set by the traditional method

\begin{tabular}{|c|c|c|c|c|c|c|c|c|}
\hline & 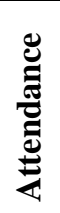 & 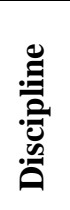 & 言 & & 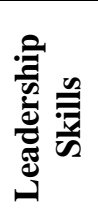 & 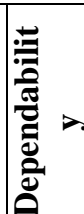 & صٌ & 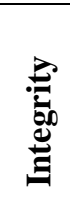 \\
\hline $\begin{array}{l}\text { eight } \\
\%\end{array}$ & 5 & 10 & 10 & 20 & 15 & 10 & 15 & 15 \\
\hline
\end{tabular}

In order to realize this, each category is evaluated by fuzzy logic, and a comprehensive evaluation of 3 categories is performed by the Neural-Network. By conducting the comprehensive evaluation in Neural-Network, it is possible to realize the evaluation logic tuned according to the immediate supervisor or managing department's judgment.

It is difficult to ensure the validity of the evaluation value of each category calculated by fuzzy logic, but this problem can be addressed by a comprehensive evaluation with a tuned Neural Network. Since the coefficients of Neural Network can be tuned to the manager's evaluation results, the logic of the overall judgment can be adjusted to the characteristics of the department. An example of such differences can be seen with the evaluation logic of the R\&D department where one considers the creative ability of an employee more important while the evaluation logic of the Sales department gives more importance to the sincere customer service provided by the employee. Therefore, the proposed system tunes the Neural-Network coefficient that responds to the different evaluation logic being made. Since the evaluation by this system is performed with the same evaluation logic as objective input values, the objectivity and transparency of the evaluation are extremely high. 
The output utilized 100 employees to reveal the difference between the traditional evaluation method and Neuro-Fuzzy network. The number of samples indicated are arbitrary and is used to configure the network. The ANN result is an output that have combined values that are both continuous and binary. For the promotion output, the value is continuous that can be further modified and tuned according to the preferential weights assigned by the manager. While for the needs improvement and termination output, the value is binary that will enable managers to decide whether to provide further training or to terminate employment.

Unlike the traditional method, the output in the neuro-fuzzy profiling system profiles the employee according to three important areas namely: achievement, leadership and behavior. Each of these areas are subject to two or more category traits. If the employee fails with at least one of the criteria, he automatically fails with that particular major profile while those employees who pass all three categories will be qualified for further evaluation which is done by the artificial neural network. This evaluation is highly recommended to sort desirable and competent employees that are due for career advancement.

Figure 16 illustrates the comparative results between the traditional evaluation system and the neuro-fuzzy profiling system. It can be seen that in the traditional system, the total score did not clearly present the correct performance of the employee. An employee may still accumulate very high scores even though he fails in 1 or 2 criteria. However, in the neuro-fuzzy profiling system, the same employee will automatically have a score of 50 that will precisely identify career development and specific relevant work-related training needs in at least one area or trait.

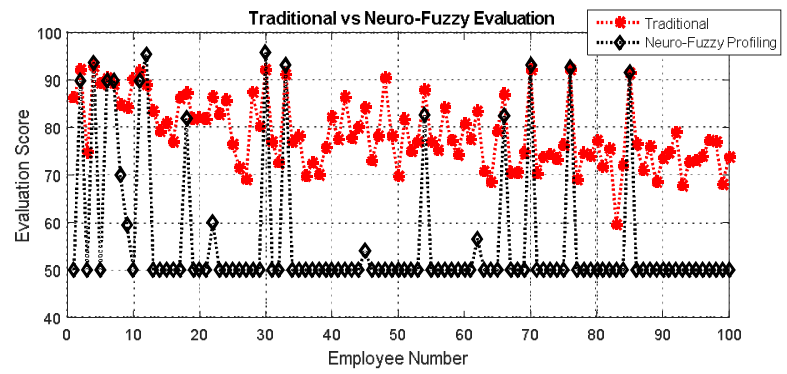

Figure 16: Comparison of Results between the traditional evaluation method and the proposed Neuro-fuzzy profiling system

To support the effectiveness of the proposed system, 5 employees are evaluated using both methods. The results are shown in Table 5 and 6 below. 
Table 5: Employee Performance Scores and Result of Traditional Evaluation

\begin{tabular}{|c|c|c|c|c|c|c|c|c|c|}
\hline \multirow[b]{2}{*}{ 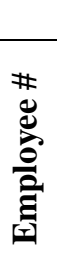 } & \multicolumn{8}{|c|}{ Criteria } & \multirow[b]{2}{*}{ 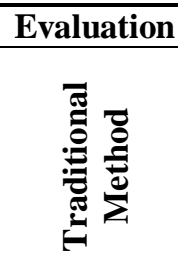 } \\
\hline & 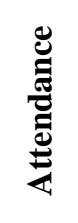 & 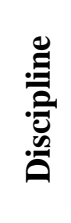 & 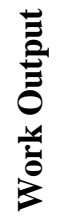 & 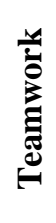 & 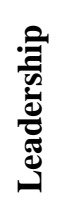 & 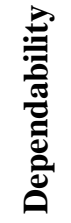 & 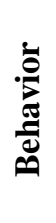 & 氙 & \\
\hline 1 & 97 & 99 & 95 & 99 & 95 & 98 & 94 & 97 & 92.30 \\
\hline 2 & 96 & 95 & 95 & 95 & 96 & 95 & 96 & 94 & 90.40 \\
\hline 3 & 100 & 100 & 87 & 98 & 90 & 95 & 93 & 97 & 90.50 \\
\hline 4 & 100 & 98 & 84 & 98 & 85 & 100 & 84 & 100 & 90.20 \\
\hline 5 & 95 & 82 & 74 & 84 & 74 & 95 & 74 & 95 & 81.60 \\
\hline
\end{tabular}

Table 6: Effectiveness of the Proposed Neuro-fuzzy Profiling system

\begin{tabular}{|c|c|c|c|c|c|c|c|c|}
\hline & \multicolumn{3}{|c|}{$\begin{array}{l}\text { Fuzzy Logic } \\
\text { Profiles }\end{array}$} & \multicolumn{5}{|c|}{$\begin{array}{c}\text { Neural Network Evaluation and } \\
\text { Appraisal }\end{array}$} \\
\hline 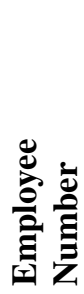 & 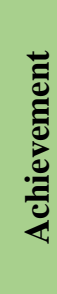 & 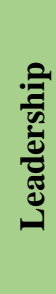 & ๑̋ & 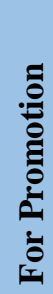 & 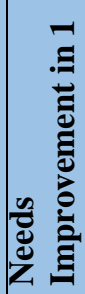 & 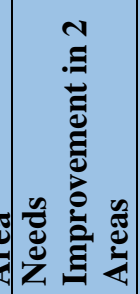 & 泀 & 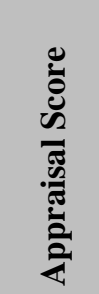 \\
\hline 1 & 90 & 88 & 95.2 & 1 & 0 & 0 & 0 & 91.50 \\
\hline 2 & 90 & 82 & 94.6 & 1 & 0 & 0 & 0 & 89.50 \\
\hline 3 & 65 & 50 & 94.9 & 0 & 1 & 0 & 0 & 0 \\
\hline 4 & 50 & 50 & 91.6 & 0 & 0 & 1 & 0 & 0 \\
\hline 5 & 50 & 50 & 50 & 0 & 0 & 0 & 1 & 0 \\
\hline
\end{tabular}

Data in Table 5 reflected that Employee 1 and 2 have both received satisfactory ratings in all categories. Employee 3 received ratings that signifies he needs improvement in one trait, while Employee 4 is weak in two traits. However, Employee 5 have received low rating scores in all traits.

With the traditional evaluation method, Employee 3, 4 and 5 have acceptable scores. This is in stark contrast to the fact that Employee 3 received a higher evaluation score than Employee 2 despite being weak in one category trait.

Table 5 reflected the employee performance scores and results of the traditional evaluation method that illustrates the deficiencies in its approximation capability as the scores are accumulated values that does not reflect the true performance weakness of an employee.

Table 6 identifies performing and non-performing employees with output decision values that were rounded off to indicate values of 0 and 1 for easier interpretation. The ANN has reshaped the output of the fuzzy logic and its function is to assist in making effective talent management decisions. For decisions regarding promotion, the judgement result is an individual score based on the tunable preferential weights assigned by the manager or department. Then, an appraisal score with a continuous value is assigned to enable managers to rank the employees accordingly. For the non-performing employees, these clearly determine decisions on which employees needs improvement in 1 or 2 areas and for termination.

The effectiveness of the proposed neuro-fuzzy profiling system optimizes the objective function in the employee quality evaluation and gives HR and organizational decision makers valuable insights to enhance employee productivity and engagement through appropriate training and development and career advancement methods. Although, it may seem that the function of the ANN in this example can be realized by simple mathematical computations, the significance of using the ANN is to show that it is possible to make judgements similar to decisions made by a manager for difficult input value patterns.

\section{CONCLUSION}

Employee performance evaluations are integral to organizations as these identifies getting, retaining and developing the best fit employees as this leads to long term overall business success.

Organizations currently use several employee evaluation performance methods that utilizes different approaches that are usually inaccurate and subjective by nature. The fuzzy profiling system was tested for accuracy with 100 employees that revealed individual ratings of non-performing employees 
receiving a rating below the assigned cut off value score of 50 and performing employees demonstrating commendable rating scores. The weights assigned in each categorical trait in the employee performance evaluation can be adjusted based on the needs of the organization and would not affect the quality and consistency of the proposed intelligent system.

Furthermore, the proposed neuro-fuzzy profiling system optimizes the objective function in the employee quality evaluation and determines the most distinctive employees deserving of career advancement or those who further needs appropriate training and development in the achievement, leadership and behavior categories.

This enables HR and decision makers in the organization to truly understand employee strengths and weaknesses that is also an essential part in promoting a positive company culture unlike the traditional employee performance evaluation methods still being adopted by many organizations at present that is impaired with unreliability and rating errors.

\section{REFERENCES}

[1] Tawarish, M., \& Satyanarayana, K. "An enabling tecnique analysis in data mining for stock market trend by approaching genetic algorithm". International Journal of Advanced Trends in Computer Science and Engineering, Vol. 8.1, pp. 2733, 2019. https://doi.org/10.30534/ijatcse/2019/06812019

[2] Golec, A., \& Kahya, E. "A fuzzy model for competency-based employee evaluation and selection". Computers \& Industrial Engineering, Vol. 52.1, pp. 143-161, 2007. https://doi.org/10.1016/j.cie.2006.11.004

[3] Macwan, N., \& Sajja, P. S. "Modeling performance appraisal using soft computing techniques: Designing neuro-fuzzy application". International conference on intelligent systems and signal processing (ISSP), pp. 403-407, IEEE, 2013. https://doi.org/10.1109/ISSP.2013.6526943

[4] Ozkan, C., Keskin, G. A., \& Omurca, S. I. "A variant perspective to performance appraisal system: fuzzy c- means algorithm". International Journal of Industrial Engineering, Vol 21.3, 2014.

[5] Yong-Xiu, C., \& Su, C. "University Innovative Personnel Assessment Research Based on Neural Network". International Conference on Intelligent Transportation, Big Data and Smart City. pp. 963966, IEEE. 2015.

https://doi.org/10.1109/ICITBS.2015.244

[6] Macwan, N., \& Sajja, P. S. "Performance appraisal using fuzzy evaluation methodology". International Journal of Engineering and Innovative Technology, Vol. 3.3, pp. 324-329, 2013.

[7] Beheshti, H. M., \& Lollar, J. G. "Fuzzy logic and performance evaluation: discussion and application". International Journal of Productivity and Performance Management, Vol. 57.3, pp. 237246, 2008.

https://doi.org/10.1108/17410400810857248

[8] Bhanuprakash, C., Nijagunarya, Y. S., \& Jayaram, M. A. "Clustering of Faculty by Evaluating their Appraisal Performance by using Feed Forward Neural Network Approach". International Journal of Intelligent Systems and Applications, Vol. 9.3, pp. 34, 2017.

https://doi.org/10.5815/ijisa.2017.03.05

[9] Villanueva, L., \& Gustilo, R.C. "Artificial neural network based antenna sensitivity assignments for chaotic Internet Service Provider network architecture", International Journal of Engineering and Technology (UAE), Vol. 7.2, pp. 14-17, 2018. https://doi.org/10.14419/ijet.v7i2.3.9958

[10] Hilado, S.D.F., Dadios, E.P., \& Gustilo, R.C., "Face detection using neural networks with skin segmentation", Proceedings of the 2011 IEEE 5th International Conference on Cybernetics and Intelligent Systems, CIS 2011, pp. 261-265, 2011. https://doi.org/10.1109/ICCIS.2011.6070338

[11] Tawarish, M., \& Satyanarayana, K. "A review on pricing prediction on stock market by different techniques in the field of data mining and genetic algorithm". International Journal of Advanced Trends in Computer Science and Engineering, Vol. 8.1, pp. 23-26, 2019 https://doi.org/10.30534/ijatcse/2019/05812019 